\title{
Steroids accumulate in the rearing water of commercial recirculating aquaculture systems
}

\author{
Vasco C. Mota ${ }^{\mathrm{a}, \mathrm{b}, *}$, Catarina I.M. Martins ${ }^{\mathrm{b}, 1}$, Ep H. Eding ${ }^{\mathrm{a}}$, \\ Adelino V.M. Canário ${ }^{\mathrm{b}}$, Johan A.J. Verreth ${ }^{\mathrm{a}}$ \\ a Aquaculture and Fisheries Group, Wageningen University, P.O. Box 338, 6700 AH Wageningen, The Netherlands \\ b CCMAR - Centro de Ciências do Mar, Universidade do Algarve, Campus de Gambelas, 8005-139 Faro, Portugal
}

\section{A R T I C L E I N F O}

\section{Article history:}

Received 31 January 2014

Accepted 8 July 2014

Available online 23 July 2014

\section{Keywords:}

Steroids in water

Fish

Cortisol

Testosterone

11-Ketoteststerone

17,20 $\beta$-Dihydroxypregn-4-en-3-one

\begin{abstract}
A B S T R A C T
Little information is available on steroid concentrations in the rearing water of aquaculture systems and whether they accumulate in recirculating aquaculture systems (RAS). Therefore this study aimed at determining (1) the concentrations and variation of cortisol and sex steroids in RAS, (2) the contribution of fish rearing conditions to steroid concentrations in seven commercial RAS. Each RAS was sampled twice at three different points: (1) make-up water; (2) influent and (3) effluent of the rearing unit. The results showed significant higher steroid concentrations in the influent and effluent when compared with the make-up water. On average cortisol concentration was $15.7 \%$ higher in the effluent when compared with the influent. Mean steroid concentrations in the rearing unit effluent varied between: 3.8-217.0 ng/L for cortisol, 3-12.5 ng/L for testosterone, 0.9-7.1 ng/L for 11-ketoteststerone and 1.8-12.8 ng/L for 17,20ß-dihydroxypregn-4-en-3-one. Stocking density, Total Ammonia-Nitrogen concentration and orthophosphate-P concentration (a measure of make-up water usage) showed a positive correlation with sex steroids in the water. The steroid concentrations from the present study were orders of magnitude lower than initial estimations indicating a water treatment efficiency of $>99 \%$. The results suggest that an intensification of fish production through decrease of make-up water use and increase of stocking density will lead to a build-up of steroids in the water. Although intensification is critical for the economical success of RAS, this ultimately could affect fish performance as steroids accumulates in the water of RAS at levels that can potentially be detected by some fish species.
\end{abstract}

() 2014 Elsevier B.V. All rights reserved.

\section{Introduction}

Recirculating aquaculture systems (RAS) are among the most environmentally sustainable systems to culture fish due to their reduced make-up water usage (new water supply) and release of nutrients to the environment (Martins et al., 2010). In response to the increasing demand for aquaculture products, production methods in RAS have been intensified. Intensification of fish production

Abbreviations: RAS, recirculating aquaculture systems; $17,20 \beta-P, 17,20 \beta-$ dihydroxypregn-4-en-3-one; TA-N, Total Ammonia-Nitrogen; TFA, trifluoroacetic acid; RIA, radioimmunoassay; TLC, thin-layer chromatography; CV, coefficient of variation.

* Corresponding author at: Aquaculture and Fisheries Group, Wageningen University, P.O. Box 338, 6700 AH Wageningen, The Netherlands. Tel.: +31 317483307; fax: +31317483962 .

E-mail address: motvasco@gmail.com (V.C. Mota).

1 Present address: Marine Harvest ASA, Sandviksboder 77AB, Pb. 4102 Sandviken, 5835 Bergen, Norway. is achieved by increasing stocking densities, which increases the amount of metabolites released into the water (Fanouraki et al., 2008). However, intensification of fish production may not always result in optimal rearing conditions.

It is known that situations eliciting the production of fish steroids, will increase their release into the water and ultimately bioaccumulation in RAS (Scott et al., 2008). Studies with rainbow trout Oncorhynchus mykiss (Ellis et al., 2004) and Atlantic salmon Salmo salar (Ellis et al., 2007) showed that the stress hormone cortisol is released at higher quantities into the water after exposure to acute handling stress. European sea bass Dicentrarchus labrax kept at stocking densities of $50 \mathrm{~kg} / \mathrm{m}^{3}$ increased both blood plasma concentrations and cortisol release rates into water when compared to fish kept at $20 \mathrm{~kg} / \mathrm{m}^{3}$ (Fanouraki et al., 2008). Other steroid hormones potentially accumulating in RAS are sex steroids such as testosterone, 11-ketotestoterone and the maturation-inducing steroid 17,20 3 -dihydroxypregn-4-en-3-one $(17,20 \beta-P)$. Sex steroids can be transferred from one group of fish to another group of fish (Budworth and Senger, 1993) as reported 
Table 1

Overview of the rearing unit, water treatment unit and water quality parameters of the seven sampled RAS. Values are mean $(N=2$, except RAS 1 where $N=1)$.

\begin{tabular}{|c|c|c|c|c|c|c|c|}
\hline & RAS 1 & RAS 2 & RAS 3 & RAS 4 & RAS 5 & RAS 6 & RAS 7 \\
\hline \multicolumn{8}{|l|}{ Rearing unit ${ }^{\mathrm{a}}$} \\
\hline Species & Solea solea & Anguilla anguilla & Psetta maxima & Stizostedion lucioperca & Clarias gariepinus & Oreochromis niloticus & Seriola lalandi \\
\hline Common name & Dover sole & European eel & Turbot & Pike-perch & African Catfish & Nile tilapia & Yellowtail amberjack \\
\hline Fish tanks & Raceways & Circular & Raceways & Circular & Rectangular & Rectangular & Circular \\
\hline Standing stock (kg) & 20,000 & & 65,000 & 7500 & 6000 & 4750 & 19,000 \\
\hline Stocking density $\left(\mathrm{kg} / \mathrm{m}^{3}\right)$ & 104 & 175 & 59 & 43 & 162 & 68 & 50 \\
\hline Feed load $(\mathrm{kg} / \mathrm{d})$ & 60 & 300 & 331 & 48 & 100 & 48 & 180 \\
\hline Weight range (g) & $16-555$ & $5-1500$ & $8-2500$ & $370-1800$ & $100-1500$ & $100-800$ & $400-1800$ \\
\hline Sex ratio $(M: F)$ & $1: 3$ & $9: 1$ & Unknown & $1: 1$ & $1: 1$ & $1: 1$ & Unknown \\
\hline Volume $\left(\mathrm{m}^{3}\right)$ & 193 & 200 & 1100 & 175 & 37 & 70 & 378 \\
\hline \multicolumn{8}{|l|}{ Water treatment unit $^{\mathrm{a}}$} \\
\hline Mechanical filtration & Drum & Drum & Drum & Drum & Settling & Sieves/settling & Drum \\
\hline Bio-reactor & Trickling & Trickling & Moving bed & Trickling & Trickling & Trickling & Trickling \\
\hline Ozone & Present & - & Present & - & - & - & - \\
\hline UV & - & - & - & - & Present & - & Present \\
\hline Make-up water (L/kg feed/d) & 1000 & 480 & 920 & 450 & 100 & 74 & 1000 \\
\hline Volume $\left(\mathrm{m}^{3}\right)$ & 7 & 30 & 2500 & 25 & 13 & 10 & 122 \\
\hline \multicolumn{8}{|l|}{ Water quality } \\
\hline Temperature $\left({ }^{\circ} \mathrm{C}\right)^{\mathrm{a}}$ & 19 & 24 & 17 & 25 & 26 & 24 & 21 \\
\hline $\mathrm{pH}^{\mathrm{a}}$ & 5.9 & 5.5 & 7.7 & 6.2 & 6.6 & 7.5 & 7.7 \\
\hline Conductivity $(\mu \mathrm{s} / \mathrm{cm})^{\mathrm{a}}$ & 40,600 & 2500 & 40,000 & 1900 & 4000 & 4200 & 36,300 \\
\hline $\mathrm{TA}-\mathrm{N}(\mathrm{mg} / \mathrm{L})^{\mathrm{b}}$ & 5.7 & 63.5 & 0.3 & 1.4 & 48.8 & 5.9 & 1.0 \\
\hline Nitrite-N (mg/L) ${ }^{\mathrm{b}}$ & 0.14 & 0.15 & 0.05 & 0.22 & 4.6 & 1.3 & 0.31 \\
\hline Nitrate-N $(\mathrm{mg} / \mathrm{L})^{\mathrm{b}}$ & 64.5 & 92.3 & 27.0 & 91.1 & 53.5 & 72.3 & 73.6 \\
\hline Orthophosphate-P (mg/L) & 4.9 & 21.6 & 2.1 & 7.1 & 13.1 & 6.5 & 5.0 \\
\hline
\end{tabular}

Fish sexual maturation: immature in RAS 1, 2, 3, 4, 5 and 7 and 90\% of the standing stock mature in RAS 6, according to information provided by the facility managers.

a Value or information provided by the facility manager.

b Value measured.

for rainbow trout (Vermeirssen and Scott, 1996) and tench Tinca tinca (Scott et al., 2005).

Besides acting as endogenous signals, steroids are also used by fish as exogenous signals, e.g. pheromones that synchronize gamete maturation or spawning interactions (Stacey, 2003). For instance, three steroids (androstenedione, 17,20 $\beta-P$ and $17,20 \beta-P$ sulphate) that are released by female goldfish Carassius auratus can elicit behavioural and physiological changes in males at very low concentrations (nM threshold) (Stacey and Sorensen, 2006). In addition, testosterone is reported to be a potent odorant in precocious male Atlantic Salmon parr (Moore and Scott, 1991).

Whether steroids in RAS occur at concentrations that can be sensed or taken up by fish remains to be investigated. Therefore the present study aimed at determining (1) the concentrations and variation of cortisol and sex steroids in RAS (2) the contribution of fish rearing conditions to the concentration of steroids in RAS.

\section{Materials and methods}

\subsection{Sampling sites and sample collection}

Water samples were collected from seven commercial recirculating aquaculture systems (RAS) in full operation located in The Netherlands. None of these RAS were in the start up phase. Details of the systems (rearing unit, water treatment unit and water quality) provided by the facilities managers are presented in Table 1. Five different commercial RAS were sampled twice with an interval of \pm 15 months, one sampled twice (RAS 7) with and interval of \pm 2 months and one RAS (1) was sampled once (the farm closed down during the second sampling period). Three different points were sampled in each RAS: (1) make-up water; (2) influent of rearing unit and; (3) effluent of rearing unit (Fig. 1).

Water samples for steroid analysis were collected in $1 \mathrm{~L}$ containers and immediately placed on ice water, transported to the laboratory and stored at $-20^{\circ} \mathrm{C}$. Additional water samples $(10 \mathrm{~mL})$ were taken (Fig. 1), placed on ice water and transported to the laboratory for Total Ammonia-Nitrogen (TA-N), Nitrite-N, Nitrate$\mathrm{N}$ and Orthophosphate-P analysis using a SAN autoanalyzer (Skalar, The Netherlands). Temperature, $\mathrm{pH}$, and conductivity were measured at the sampling sites using portable meters or provided by the facilities managers. Nitrile gloves were used during all water sampling and processing activities to prevent contamination with steroids.

\subsection{Steroid analysis}

Steroid hormones were measured by radioimmunoassay of their free forms. For this it required extraction of steroids from the water and hydrolysis of conjugates to release the free forms as previously reported (Canario and Scott, 1989; Scott and Sorensen, 1994). Briefly, water samples for steroid analysis were first paper filtered ( $2 \mu \mathrm{m}$; VWR, France) followed by a membrane filter $(0.45 \mu \mathrm{m}$; Millipore, Ireland). The sample volume $( \pm 500 \mathrm{~mL})$ was determined gravimetrically and pumped $( \pm 12 \mathrm{~mL} / \mathrm{min})$ through an Oasis HLB Plus solid phase extraction cartridge (Oasis ${ }^{\circledR}$, Waters, Milford, U.S.A.) previously activated with methanol $(5 \mathrm{~mL})$ and washed with distilled water $(5 \mathrm{~mL})$. Cartridges were eluted ( $3 \mathrm{~mL} 100 \%$ ethanol) and the eluate evaporated in a dry bath at $45^{\circ} \mathrm{C}$ under a gentle flow of nitrogen. The dried residue was re-dissolved in $0.1 \mathrm{~mL}$ distilled water, $3 \times 3 \mathrm{~mL}$ of diethyl ether was added, the tubes vigorously shaken, and centrifuged at low speed to separate the organic and water phases. The water phase was frozen in liquid nitrogen. The diethyl ether was transferred to another tube and evaporated under nitrogen. To the residue was re-constituted in radioimmunoassay (RIA) buffer (sodium phosphate $0.05 \mathrm{M}, \mathrm{pH} 7.6$, containing $1 \%$ gelatine) and stored $\left(-20^{\circ} \mathrm{C}\right)$ until assay.

The remaining aqueous fraction containing the conjugated steroids was evaporated at $40^{\circ} \mathrm{C}$ and $1 \mathrm{~mL}$ of trifluoroacetic acid (TFA)/ethyl acetate $(1 / 100, v / v)$ was added to the dried residue and incubated in a water bath at $40^{\circ} \mathrm{C}$ overnight for the chemical hydrolysis of the sulphate steroids. The TFA/ethyl acetate was subsequently evaporated in a dry bath at $45^{\circ} \mathrm{C}$ under a gentle nitrogen flow and the dried residue was re-dissolved in $0.5 \mathrm{~mL}$ sodium 


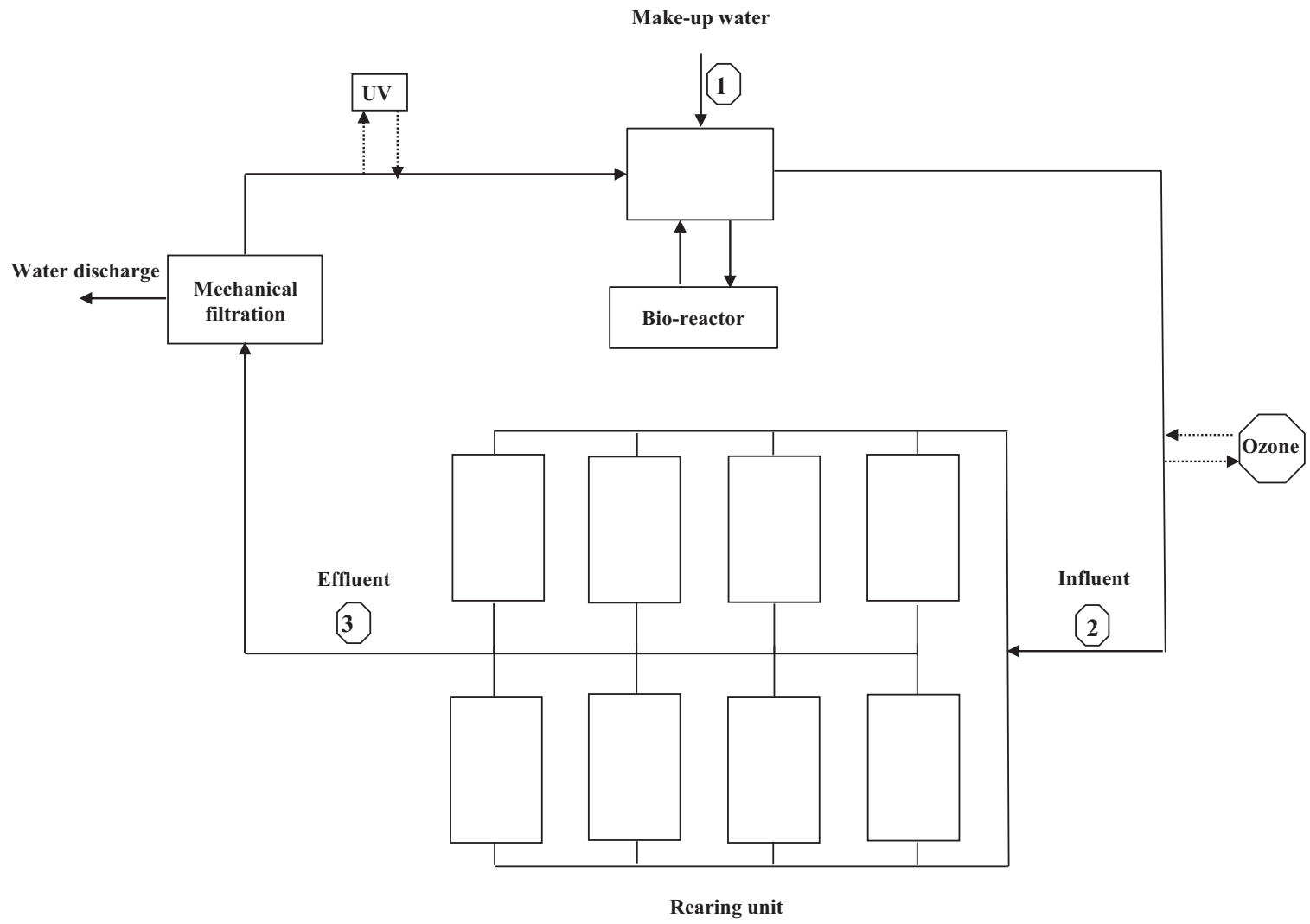

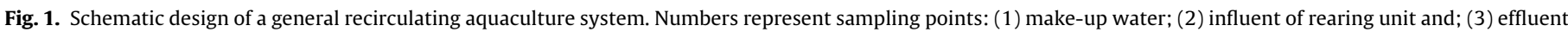

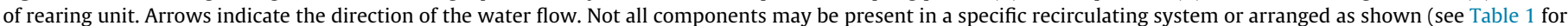
detailed information).

$0.1 \mathrm{M}$ acetate buffer $\mathrm{pH}$ 4.5. The sulphate steroid fraction (now free steroids) was extracted and radioimmunoassay buffer added as described above.

Finally, traces of diethyl ether were removed from the sodium acetate by a gentle stream of nitrogen and $\beta$-glucuronidase $(10 \mu \mathrm{L})$ from Helix pornatia (Sigma-Aldrich, U.S.A.) was added and incubated at $37^{\circ} \mathrm{C}$ overnight for the enzymatic hydrolysis of the steroid glucuronides. The steroid glucuronide hydrolysates were extracted $3 \times$ with diethyl ether as described above, radioimmunoassay buffer added and stored at $-20^{\circ} \mathrm{C}$ until assay.

The methodology for steroid RIA is described by Scott et al. (1982). For cortisol antiserum 20-CR50 (Fitzgerald Industries International, Concord, USA) and tritiated cortisol (GE Healthcare Europe $\mathrm{GmbH}$, Carnaxide, Portugal) were used. Cross-reactions were $54 \%$ for 11 -desoxycortisol, $10 \%$ for cortisone, $16 \%$ for 17,21 -dihydroxy-5 $\beta$-pregnan-3,11,20-trione, $5 \%$ for $11 \beta, 17,21$-trihydroxy-5 $\beta$-pregnan-3,20-dione, $0.05 \%$ for $11 \beta$ hydroxytestosterone and less than $0.001 \%$ for testosterone (Rotllant et al., 2005). The testosterone and 11-ketotestosterone antisera were kindly donated by Dr. David Kime (University of Sheffield, UK). The testosterone antiserum cross-reactions were $63 \%$ for androstenedione, $35 \%$ for 11 -ketotestosterone, $55 \%$ for $11 \beta$ hydroxytestosterone, $40 \%$ for $5 \alpha$-androstan- $17 \beta$-ol-3-one, $31 \%$ for $5 \beta$-androstan- $17 \beta$-ol-3-one, $12 \%$ for $5 \beta$-androstane- $3 \alpha, 17 \beta$-diol, $25 \%$ for $5 \alpha$-androstane- $3 \alpha, 17 \beta$-diol. The 11 -ketotestosterone antiserum cross-reactions are given elsewhere (Kime and Manning, 1982 ) and were $20.1 \%$ for $11 \beta$-hydroxytestosterone, $20.6 \%$ for testosterone, $76.9 \%$ for androstenetrione, $30.1 \%$ for $11 \beta$ hydroxyandrostenedione, $52 \%$ for dihydrotestosterone, $3.3 \%$ for cortisol and $1.3 \%$ for cortisone. The $17,20 \beta-P$ antiserum was donated by Dr. A.P. Scott and characterized by Scott et al. (1982, 1997).
The mean recovery efficiency for steroids was $84 \%$ (unspiked RAS (without fish) water samples contained $0.7 \pm 0.2 \mathrm{ng} / \mathrm{L}$ and contained $76.4 \pm 4.8 \mathrm{ng} / \mathrm{L}$ after samples were spiked with $87 \mathrm{ng} / \mathrm{L}$ cortisol (hydrocortisone H4001, Sigma-Aldrich, The Netherlands). The observed recovery is in line with the reported recovery in literature 87\% (Ellis et al., 2004) and 85\% (García-López et al., 2006). RIA detection limit was $36 \mathrm{pg} / \mathrm{L}$ for cortisol, $60 \mathrm{pg} / \mathrm{L}$ for testosterone, $50 \mathrm{pg} / \mathrm{L}$ for 11 -ketotestosterone and $80 \mathrm{pg} / \mathrm{L} 17,20 \beta-P$.

Cross-reactivity of water samples with antisera was verified by thin-layer chromatography (TLC). Briefly, the analysis was performed from the dried residue extracts previously obtained and applied to a pre-coated silica gel TLC plates (LK6DF silica gel $60 \mathrm{~A}$ plates, Whatman Inc., NJ, USA). The plates were developed at room temperature for $50 \mathrm{~min}$, using as mobile phase chloroform:methanol (72:3). Tritiated standard steroids were aliquoted in distinct lanes (cortisol, testosterone, 11-ketotestosterone and $17 \alpha, 20 \beta$-dihydroxy-4-pregnen-3-one) and used as reference. Each water sample lane was divided in $0.5 \mathrm{~cm}$ strips that were scraped, eluted with dichloromethane: ethanol $(8: 2, \mathrm{v} / \mathrm{v}, 2 \times 1 \mathrm{~mL})$ and evaporated under vacuum centrifugation at $40^{\circ} \mathrm{C}$. The residue was dissolved in $1 \mathrm{~mL}$ RIA assay buffer.

\subsection{Data analysis}

Homogeneity of variances was tested using Levene's test. Steroid analysis of make-up water, influent and effluent of the rearing unit was done using the average from the two sampling periods followed by an Independent Students $t$-test. Analysis of rearing conditions, i.e., standing stock, stocking density, total volume (rearing unit + water treatment unit), make-up water, temperature, $\mathrm{pH}$, conductivity, TA-N, Nitrite- $\mathrm{N}$, Nitrate- $\mathrm{N}$, orthophosphate-P on effluent of rearing unit steroid concentrations was tested 

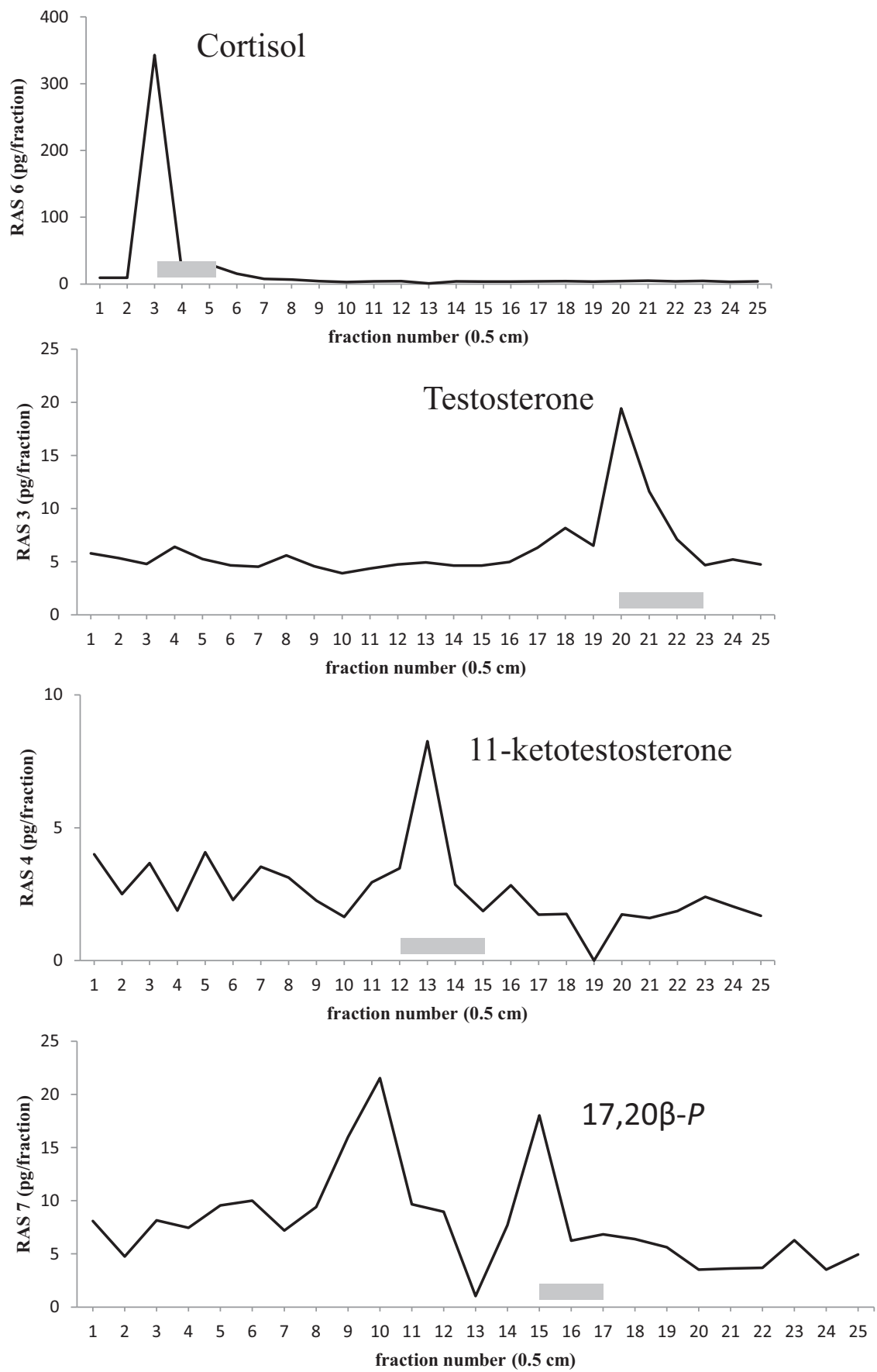

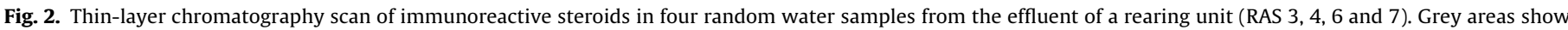
elution positions of the tritiated standards (1) cortisol, (2) testosterone, (3) 11-ketotestosterone and (4) 17,20 3 -P.

by Pearson's correlations. For Pearson's correlations the $\alpha$ was recalculated after Bonferroni correction for multiple tests (initial $\alpha=0.05 / 16=0.003)$. Statistical analysis was performed with IBM SPSS Statistics 19 (IBM Corp., USA). A significance level ( $\alpha$ ) of 0.05 was used. Data are presented as mean \pm standard deviation (s.d.).

\section{Results}

\subsection{Steroid concentration and variation}

Analysis of water extracts on TLC showed a single peak for each steroid, except for $17,20 \beta-P$ which cross-reacted also with a secondary less polar compound (Fig. 2). All steroid concentrations were higher in the influent and effluent of rearing unit when compared to make-up water (Fig. 3). Overall total cortisol concentration was $15.7 \%$ higher in the effluent when compared with the influent (Table 2). Sex steroids showed a smaller nonsignificant increase in concentration between influent and effluent. Also notable is the $53.8 \%$ overall increase of cortisol sulphate between influent and effluent that contrasted with the overall decrease of the other steroid sulphates (Table 2). Total cortisol concentrations (max. $217.0 \mathrm{ng} / \mathrm{L}$ ) were higher when compared to total testosterone (max. $13.7 \mathrm{ng} / \mathrm{L}$ ), total 11-ketoteststerone (max. $6.4 \mathrm{ng} / \mathrm{L}$ ) and total 17,20ß-P (max. $12.8 \mathrm{ng} / \mathrm{L}$ ) (Tables 3a and $3 \mathrm{~b}$ ). 

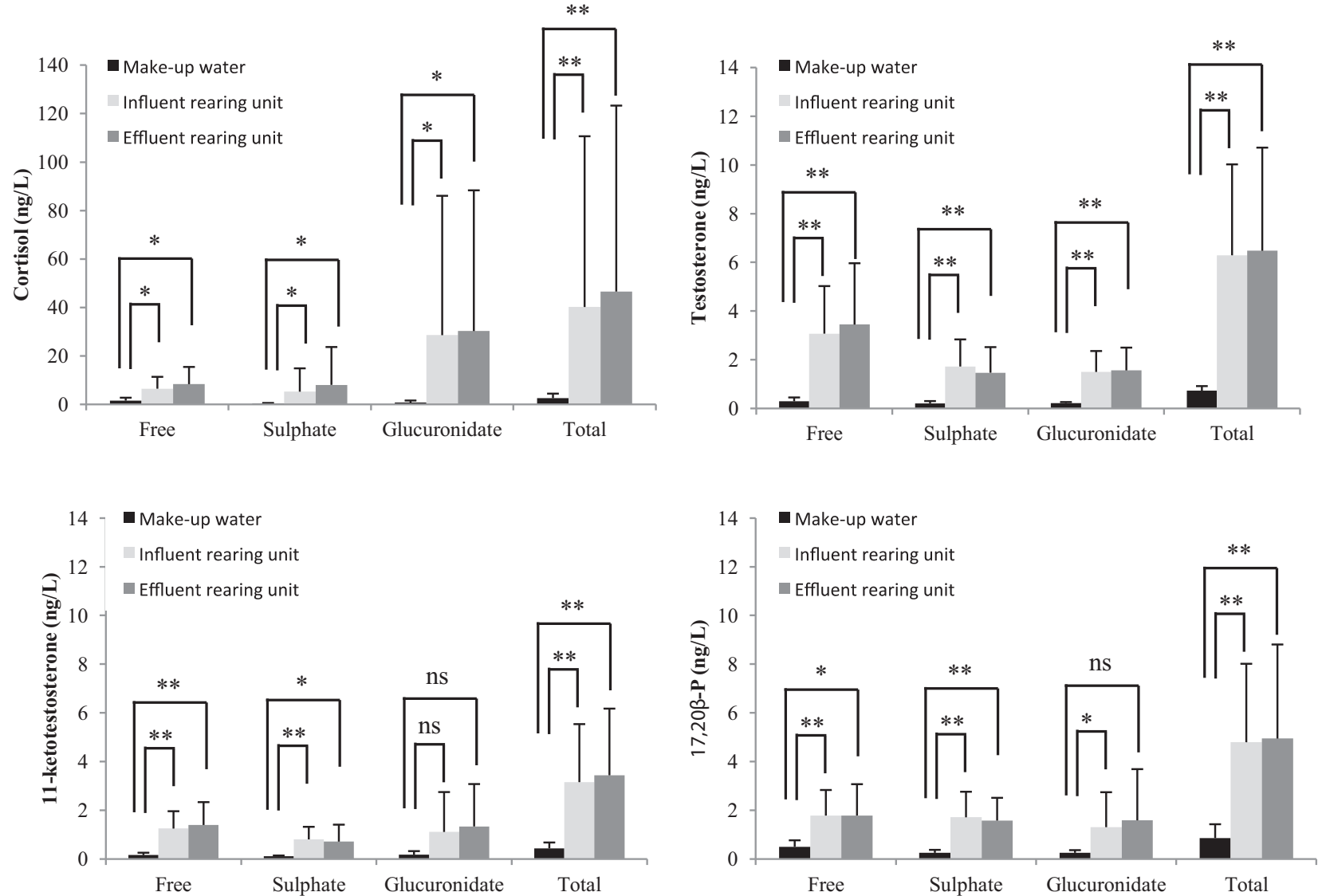

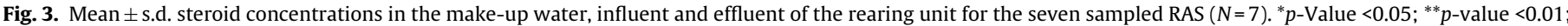
*** $p$-value $<0.001$; ns - not significant.

Total cortisol also exhibited the highest variation among the different RAS (CV 163.0\%) when compared to the sex steroids (total testosterone $=68.2 \%$, total 11 -ketotestosterone $=80.4 \%$, total $17,20 \beta-P=78.3 \%)$. Higher variation in cortisol concentration was also observed between the two sampling periods, particularly in RAS 4 (CV = 94.6\%; Table 3b).

\subsection{Steroid concentration and rearing condition}

Table 4 shows the correlations between water steroid concentrations and rearing conditions. Testosterone and 11ketotestosterone showed a significant and positive correlation with stocking density, TA-N and orthophosphate-P. None of the other

Table 2

Mean \pm s.d. steroid concentrations in the influent and effluent of the rearing unit for the seven sampled RAS $(N=7)$.

\begin{tabular}{|c|c|c|c|c|}
\hline Steroids (ng/L) & Influent of rearing unit & Effluent of rearing unit & $p$-Value & Overall increase (\%) \\
\hline \multicolumn{5}{|l|}{ Cortisol } \\
\hline Free & $6.4 \pm 4.9$ & $8.3 \pm 7.1$ & 0.343 & 29.7 \\
\hline Sulphate & $5.2 \pm 9.6$ & $8.0 \pm 15.6$ & 0.103 & 53.8 \\
\hline Glucuronide & $28.5 \pm 57.5$ & $30.2 \pm 58.1$ & 0.334 & 6.0 \\
\hline Total & $40.2 \pm 70.5$ & $46.5 \pm 76.8$ & $0.047^{*}$ & 15.7 \\
\hline \multicolumn{5}{|l|}{ Testosterone } \\
\hline Free & $3.1 \pm 2.0$ & $3.4 \pm 2.5$ & 0.296 & 9.7 \\
\hline Sulphate & $1.7 \pm 1.1$ & $1.5 \pm 1.0$ & 0.070 & -11.8 \\
\hline Glucuronide & $1.5 \pm 0.9$ & $1.6 \pm 0.9$ & 0.711 & 6.7 \\
\hline Total & $6.3 \pm 3.7$ & $6.5 \pm 4.2$ & 0.825 & 3.2 \\
\hline \multicolumn{5}{|c|}{ 11-Ketotestosterone } \\
\hline Free & $1.2 \pm 0.7$ & $1.4 \pm 0.9$ & 0.327 & 16.7 \\
\hline Sulphate & $0.8 \pm 0.5$ & $0.7 \pm 0.7$ & 0.520 & -12.5 \\
\hline Glucuronide & $1.1 \pm 1.6$ & $1.3 \pm 1.7$ & 0.054 & 18.2 \\
\hline Total & $3.2 \pm 2.4$ & $3.4 \pm 2.7$ & 0.646 & 6.3 \\
\hline \multicolumn{5}{|l|}{$17,20 \beta-P$} \\
\hline Free & $1.8 \pm 1.0$ & $1.8 \pm 1.3$ & 0.605 & 0.0 \\
\hline Sulphate & $1.7 \pm 1.0$ & $1.6 \pm 0.9$ & 0.514 & -5.9 \\
\hline Glucuronide & $1.3 \pm 1.4$ & $1.6 \pm 2.1$ & 0.500 & 23.1 \\
\hline Total & $4.8 \pm 3.2$ & $4.9 \pm 3.9$ & 0.959 & 2.1 \\
\hline
\end{tabular}

${ }^{*}$ Indicates significant effect $(p$-value $<0.05)$. 
Table 3a

Mean \pm s.d. steroid concentrations in the influent of the rearing unit for the seven sampled RAS ( $N=2$, except when there is no s.d. where $N=1)$.

\begin{tabular}{|c|c|c|c|c|c|c|c|c|}
\hline Steroids (ng/L) & RAS 1 & RAS 2 & RAS 3 & RAS 4 & RAS 5 & RAS 6 & RAS 7 & Overall CV (\%) \\
\hline \multicolumn{9}{|l|}{ Cortisol } \\
\hline Free & 13.7 & $8.2 \pm 7.9$ & $0.8 \pm 0.0$ & $6.6 \pm 4.0$ & $3.8 \pm 0.3$ & $11.9 \pm 7.3$ & $1.7 \pm 0.4$ & 73.8 \\
\hline Sulphate & 27.0 & $1.4 \pm 0.6$ & $1.2 \pm 0.3$ & $2.6 \pm 0.6$ & $1.2 \pm 0.6$ & $1.4 \pm 0.6$ & $1.7 \pm 1.2$ & 184.2 \\
\hline Glucuronide & 157.7 & $12.0 \pm 3.9$ & $1.6 \pm 1.7$ & $23.8 \pm 19.6$ & $1.8 \pm 0.3$ & $1.3 \pm 0.8$ & $2.6 \pm 2.0$ & 200.5 \\
\hline Total & 198.4 & $21.6 \pm 12.4$ & $3.6 \pm 2.0$ & $33.0 \pm 23.1$ & $6.9 \pm 0.5$ & $14.6 \pm 7.0$ & $6.0 \pm 0.5$ & 173.3 \\
\hline \multicolumn{9}{|l|}{ Testosterone } \\
\hline Free & 2.7 & $6.9 \pm 3.1$ & $1.0 \pm 0.2$ & $1.6 \pm 0.2$ & $5.1 \pm 0.8$ & $3.4 \pm 0.2$ & $1.5 \pm 0.0$ & 67.8 \\
\hline Sulphate & 0.8 & $3.0 \pm 2.6$ & $0.8 \pm 0.1$ & $0.6 \pm 0.7$ & $3.5 \pm 3.3$ & $2.6 \pm 0.3$ & $1.5 \pm 0.4$ & 65.8 \\
\hline Glucuronide & 1.6 & $3.1 \pm 2.6$ & $0.7 \pm 0.2$ & $0.4 \pm 0.1$ & $2.3 \pm 1.6$ & $2.1 \pm 1.7$ & $0.8 \pm 0.6$ & 63.0 \\
\hline Total & 5.0 & $13.0 \pm 8.2$ & $2.4 \pm 0.5$ & $2.6 \pm 1.0$ & $11.0 \pm 5.7$ & $8.1 \pm 1.6$ & $3.8 \pm 0.2$ & 63.7 \\
\hline \multicolumn{9}{|c|}{ 11-Ketotestosterone } \\
\hline Free & 2.0 & $1.8 \pm 0.6$ & $0.3 \pm 0.1$ & $1.1 \pm 0.4$ & $2.1 \pm 0.7$ & $1.0 \pm 0.6$ & $0.6 \pm 0.2$ & 57.4 \\
\hline Sulphate & 0.8 & $1.3 \pm 0.2$ & $0.4 \pm 0.4$ & $0.1 \pm 0.0$ & $1.3 \pm 0.2$ & $1.4 \pm 1.4$ & $0.4 \pm 0.2$ & 64.8 \\
\hline Glucuronide & 4.4 & $2.8 \pm 2.4$ & $0.2 \pm 0.1$ & $0.1 \pm 0.1$ & $0.4 \pm 0.3$ & $0.2 \pm 0.0$ & $0.2 \pm 0.0$ & 144.7 \\
\hline Total & 7.2 & $5.9 \pm 3.2$ & $0.9 \pm 0.6$ & $1.3 \pm 0.5$ & $3.8 \pm 1.1$ & $2.6 \pm 1.9$ & $1.1 \pm 0.1$ & 76.7 \\
\hline \multicolumn{9}{|l|}{$17,20 \beta-P$} \\
\hline Free & 0.5 & 3.1 & 0.8 & 1.6 & 3.0 & 2.4 & 1.1 & 58.8 \\
\hline Sulphate & 1.7 & 3.3 & 0.6 & 0.5 & 2.8 & 1.6 & 2.2 & 58.8 \\
\hline Glucuronide & 0.4 & 4.4 & 0.4 & 0.9 & 1.5 & 1.0 & 0.5 & 110.9 \\
\hline Total & 2.6 & 10.8 & 1.9 & 2.9 & 7.3 & 5.0 & 3.7 & 65.1 \\
\hline
\end{tabular}

Table 3b

Mean \pm s.d. steroid concentrations in the effluent of the rearing unit for the seven sampled RAS ( $N=2$, except when there is no s.d. where $N=1$ ).

\begin{tabular}{|c|c|c|c|c|c|c|c|c|}
\hline Steroids (ng/L) & RAS 1 & RAS 2 & RAS 3 & RAS 4 & RAS 5 & RAS 6 & RAS 7 & Overall CV (\%) \\
\hline \multicolumn{9}{|l|}{ Cortisol } \\
\hline Free & 14.2 & $7.3 \pm 7.0$ & $0.8 \pm 0.0$ & $15.3 \pm 15.4$ & $3.0 \pm 1.7$ & $17.5 \pm 16.9$ & $1.7 \pm 0.9$ & 82.2 \\
\hline Sulphate & 43.4 & $1.6 \pm 0.2$ & $1.7 \pm 1.2$ & $2.3 \pm 1.4$ & $1.2 \pm 0.4$ & $1.5 \pm 0.2$ & $4.4 \pm 4.0$ & 195.4 \\
\hline Glucuronide & 159.5 & $14.3 \pm 6.5$ & $1.3 \pm 1.0$ & $32.2 \pm 30.4$ & $2.1 \pm 0.3$ & $1.1 \pm 0.6$ & $2.6 \pm 1.7$ & 190.6 \\
\hline Total & 217.0 & $23.2 \pm 13.3$ & $3.8 \pm 2.1$ & $49.9 \pm 47.2$ & $6.3 \pm 1.0$ & $20.1 \pm 16.5$ & $8.6 \pm 3.2$ & 163.0 \\
\hline \multicolumn{9}{|l|}{ Testosterone } \\
\hline Free & 1.9 & $8.6 \pm 2.3$ & $1.3 \pm 0.0$ & $1.8 \pm 0.2$ & $5.5 \pm 1.5$ & $3.8 \pm 0.8$ & $1.7 \pm 0.3$ & 76.2 \\
\hline Sulphate & 0.5 & $2.7 \pm 2.0$ & $0.7 \pm 0.2$ & $0.6 \pm 0.7$ & $3.4 \pm 2.7$ & $1.6 \pm 1.8$ & $1.3 \pm 0.1$ & 73.0 \\
\hline Glucuronide & 1.3 & $2.4 \pm 0.8$ & $0.7 \pm 0.3$ & $0.5 \pm 0.3$ & $3.2 \pm 0.9$ & $1.7 \pm 1.2$ & $1.3 \pm 0.6$ & 60.5 \\
\hline Total & 3.7 & $13.7 \pm 5.1$ & $2.7 \pm 0.5$ & $3.0 \pm 1.1$ & $12.1 \pm 5.1$ & $7.1 \pm 0.2$ & $4.2 \pm 0.2$ & 68.2 \\
\hline \multicolumn{9}{|c|}{ 11-Ketotestosterone } \\
\hline Free & 2.0 & $1.8 \pm 0.6$ & $0.2 \pm 0.0$ & $1.0 \pm 0.1$ & $3.0 \pm 1.4$ & $1.2 \pm 0.9$ & $0.6 \pm 0.0$ & 67.1 \\
\hline Sulphate & 0.5 & $1.4 \pm 0.1$ & $0.4 \pm 0.3$ & $0.2 \pm 0.0$ & $2.0 \pm 0.7$ & $0.3 \pm 0.0$ & $0.3 \pm 0.0$ & 98.1 \\
\hline Glucuronide & 4.7 & $3.2 \pm 2.2$ & $0.3 \pm 0.2$ & $0.2 \pm 0.1$ & $1.0 \pm 0.2$ & $0.1 \pm 0.0$ & $0.3 \pm 0.1$ & 129.3 \\
\hline Total & 7.1 & $6.4 \pm 2.9$ & $0.9 \pm 0.6$ & $1.4 \pm 0.2$ & $6.1 \pm 2.4$ & $1.7 \pm 0.9$ & $1.2 \pm 0.1$ & 80.4 \\
\hline \multicolumn{9}{|l|}{$17,20 \beta-P$} \\
\hline Free & 0.4 & 3.9 & 0.6 & 1.5 & 2.6 & 2.5 & $0.9 \pm 0.1$ & 72.3 \\
\hline Sulphate & 2.6 & 2.7 & 0.5 & 0.5 & 2.2 & 1.5 & $1.0 \pm 0.3$ & 60.1 \\
\hline Glucuronide & 0.5 & 6.2 & 0.7 & 0.8 & 2.1 & 0.6 & $0.3 \pm 0.1$ & 132.0 \\
\hline Total & 3.4 & 12.8 & 1.8 & 2.7 & 6.9 & 4.7 & $2.3 \pm 0.5$ & 78.3 \\
\hline
\end{tabular}

rearing conditions (standing stock, total volume, make-up water, temperature, $\mathrm{pH}$, conductivity, Nitrite-N, Nitrate-N) investigated showed a significant correlation with steroid concentrations (data not shown).

Table 4

Pearson's correlations between steroid concentrations in the effluent of rearing unit and orthophosphate-P, TA-N and stocking density $(N=13)$. Only the statistical significant correlations are shown.

\begin{tabular}{ll}
\hline Coefficients of Pearson correlation and significance & \\
\hline Orthophosphate-P $\times$ free testosterone & $0.853(p=0.001)$ \\
Stocking density $\times$ free testosterone & $0.835(p=0.001)$ \\
Stocking density $\times 1$ 1-ketotestosterone sulphate & $0.791(p=0.002)$ \\
Stocking density $\times$ total 11 -ketotestosterone & $0.801(p=0.002)$ \\
TA-N $\times$ free testosterone & $0.890(p<0.001)$ \\
TA-N $\times$ testosterone glucuronide & $0.810(p=0.001)$ \\
TA-N $\times$ total testosterone & $0.875(p<0.001)$ \\
TA-N $\times$ free 11 -ketotestosterone & $0.891(p<0.001)$ \\
TA-N $\times 11$-ketotestosterone Sulphate & $0.882(p<0.001)$ \\
TA-N $\times$ total 11-ketotestosterone & $0.899(p<0.001)$ \\
\hline
\end{tabular}

\section{Discussion}

Cortisol is the principal glucocorticoid in teleost fish and its plasma concentrations notably rise when fish are exposed to stressors (Mommsen et al., 1999) such as handling (Ellis et al., 2004, 2007) or high stocking densities (Fanouraki et al., 2008). Total cortisol concentration in the water increased $15.7 \%$ with water flowing through the rearing units (Table 2), suggesting that fish release large amounts of cortisol into the water. Commercial fish diets were suggested to be an important source of steroids: cortisol has been reported to range between 35 and $67 \mathrm{ng} / \mathrm{g}$ feed (Feist and Schreck, 1990) and sex steroids between 0.4 and $11 \mathrm{ng} / \mathrm{g}$ feed (Pelissero et al., 1989; Sower and Iwamoto, 1985). However, estimations using the average feed load $(152 \mathrm{~kg} / \mathrm{d})$ and standing stock $(22,464 \mathrm{~kg})$ in this research (Table 1 ) and cortisol release rates $(0.5-5 \mathrm{ng} / \mathrm{g} / \mathrm{h})$ reported by Fanouraki et al. (2008) suggests that fish diets only account for $0.5 \%$ of cortisol input in RAS (diets $0.008 \mathrm{~g} / \mathrm{d}$ vs. fish $1.483 \mathrm{~g} / \mathrm{d}$ ). Thus fish account for $>99 \%$ of steroids in RAS.

Notably cortisol sulphate increased between influent and effluent (53.8\%) compared to cortisol and cortisol glucuronide (Table 2). 
This result was not expected as in rainbow trout free steroids account for $40 \%$ of the total excretion (Vermeirssen and Scott, 1996). Steroid clearance in fish seems to depend on steroid lipophilicity; free steroids (lipid-soluble) diffuse into the water across the gills whereas sulphate and glucuronide steroids (lipidinsoluble steroids) are excreted via kidney (Maren et al., 1968). In rainbow trout clearance of $17,20 \beta-P$ and its conjugates follows three preferred pathways: (1) the free form via the gills, (2) the sulphate form via the urine, and (3) the glucuronide form via the bile (Ellis et al., 2005; Vermeirssen and Scott, 1996). The unexpected high cortisol sulphate increase may be related to species specificities and/or to sulphate conjugation in the rearing units. The dynamics of steroid conjugation and release has been little studied.

Sex steroids occurred at almost 10 -fold lower concentrations compared to cortisol (Fig. 3). Yet, even at these low concentrations sex steroids can be detected by the olfactory system and in some species sex steroids can act as pheromones (Sorensen et al., 1990). For instance, male goldfish can detect free $17,20 \beta-P$ and $17,20 \beta-P$ sulphate at concentrations as low as $0.3 \mathrm{ng} / \mathrm{L}\left(10^{-12} \mathrm{M}\right)$ and $3.0 \mathrm{ng} / \mathrm{L}\left(10^{-11} \mathrm{M}\right)$ (Sorensen et al., 1995). Testosterone is also able to elicit odorant responses in fish at concentrations as low as $0.003 \mathrm{ng} / \mathrm{L}$ (Moore and Scott, 1991). The 17,20ß-P and testosterone concentrations measured in RAS were in the range of $0.4-6.2 \mathrm{ng} / \mathrm{L}$ and $0.5-8.0 \mathrm{ng} / \mathrm{L}$, respectively (Tables $3 \mathrm{a}$ and $3 \mathrm{~b}$ ). This shows that RAS rearing water contains sex steroid concentrations, which can affect fish. However, there are large differences in olfactory sensitivity to steroids between species and some may be insensitive to steroid odours (Stacey, 2010). Of the species studied, only African catfish is known to produce steroid glucuronides from the seminal vesicles which function as pheromones and that females are particularly sensitive to $3 \alpha, 17 \alpha$-dihydroxy-5 $\beta$-pregnan-20-one$3 \alpha$-glucuronide (Lambert and Resink, 1991). To our best knowledge for the other species no information is available in literature.

RAS seems to be very efficient in removing steroids. Using Table 1 mean values (standing stock: $22,464 \mathrm{~kg}$; make-up water: $575 \mathrm{~L} / \mathrm{kg}$ feed; feed load: $152 \mathrm{~kg} / \mathrm{d}$ ) and a (low) cortisol release rate of $0.5 \mathrm{ng} / \mathrm{g} / \mathrm{h}$ Fanouraki et al. (2008) we would expect to find cortisol concentrations of approximately $3084 \mathrm{ng} / \mathrm{L}$. However, the steroid concentrations measured here were orders of magnitude lower (mean concentration: $10 \mathrm{ng} / \mathrm{L}$; Tables 3a and 3b), indicating a treatment efficiency of $>99 \%$. Treatment efficiencies of this order have been reported before for wastewater treatment plants (Chang et al., 2007) and variation on steroid concentrations were found to be dependent on numerous factors such as treatment type (e.g. trickling filter), optimization (e.g. hydraulic time) and competing compounds for sorption sites (Gomes et al., 2009). In wastewater treatment plants adsorption of steroids in sludge plays an important role. However, adsorption is not equal for all steroids - glucocorticoids have lower tendency to adsorb onto sludge than androgens and progestins (Liu et al., 2012). This lower adsorption of glucocorticoids, i.e. cortisol to sludge, together with its high production in the rearing units may explain the high levels of cortisol in RAS. Another possible reason for the low concentrations of sex steroids might be that all water samples were collected from grow-out systems containing sexually immature fish, except for Nile tilapia which were sexually mature.

Cortisol displayed a remarkably high variation among the seven RAS (CV: 163\%) (Table 3b). Differences in systems configuration and species responsiveness to high stocking densities could be explanatory factors. However, other factors such as ozonation and UV could also be involved as these systems had the lowest cortisol values (RAS 3, 5, 7). The exception was RAS 1 containing Dover sole which showed high cortisol in RIA. However, thin-layer chromatography analysis revealed that most of this cortisol immunoreaction was cortisone (data not shown). That, together with the measurement of cortisol in sole blood plasma and bile (not shown), indicates that cortisol was likely converted to cortisone in RAS.

Sex steroid concentrations were positively correlated with TAN. TA-N $\left(\mathrm{NH}_{3}-\mathrm{N}+\mathrm{NH}_{4}-\mathrm{N}\right)$ is a fish metabolite converted by bacteria into Nitrite-N and then in Nitrate-N in RAS bio-reactors (Eding et al., 2006). Similarly, steroids may be degraded by bacteria present in RAS as is observed in aerobic (Horinouchi et al., 2004) and anaerobic (Fahrbach et al., 2010) waste water treatments. Fish culture conditions may not be optimal for bacteria as shown by TA-N accumulation in RAS 2 and 5 . Therefore this correlation suggests that a culture factor is affecting bacteria quantity or activity in RAS. Based on Table 1 and current knowledge about the nitrification process, $\mathrm{pH}$ (low) is likely affecting bacteria on steroids removal. Sex steroid concentrations were also positively correlated with orthophosphate-P and stocking density. Orthophosphate-P water concentrations are a measure of the degree of new make-up water in RAS (Martins et al., 2009). Therefore, these results suggest that an intensification of fish production through a decrease of makeup water supply per unit of fish produced and increase of stocking density will lead to a build-up of steroids in the water. Although intensification is critical for the success of RAS, this ultimately could affect fish performance. However, whether this is the case and in what way needs to be further investigated.

In conclusion, the present study shows that the measured steroids (a glucocorticoid, two androgens and a progestin) in their free and conjugated forms are present in significant concentrations in the rearing water of commercial RAS. Cortisol displayed the highest concentrations and largest variability among RAS and over time. Furthermore, steroid concentrations in RAS are higher than those reported for flow-through systems (Kolodziej et al., 2004), which suggests that steroids tend to accumulate in closed systems at levels susceptible to be detected by fish, at least in some species. TA$\mathrm{N}$ and stocking density were the rearing condition most relevant to explain the variation of steroid concentrations in the water of RAS. Whether, the observed levels impair fish welfare and growth performance in RAS, remains to be investigated.

\section{Acknowledgments}

V.C.M. was supported by a PhD scholarship (SFRH/BD/65673/2009) funded by the Portuguese institution FCT - Fundação para a Ciência e Tecnologia (QREN-POPH Advanced Training, subsidized by the European Social Fund and national funds MEC). We gratefully acknowledge the farm owners for their cooperation and assistance and Elsa Couto for technical support with the radioimmunoassays.

\section{References}

Budworth, P.R., Senger, P.L., 1993. Fish-to-fish testosterone transfer in a recirculating-water system. Prog. Fish Cult. 55, 250-254.

Canario, A.V., Scott, A., 1989. Conjugates of ovarian steroids, including $17 \alpha, 20 \beta-$ dihydroxy-4-pregnen-3-one (maturation-inducing steroid), accumulate in the urine of a marine teleost (plaice; Pleuronectes platessa). J. Endocrinol. 123, R1-R4.

Chang, H., Hu, J., Shao, B., 2007. Occurrence of Natural and Synthetic Glucocorticoids in Sewage Treatment Plants and Receiving River Waters. Environ. Sci. Technol. 41, 3462-3468.

Eding, E.H., Kamstra, A., Verreth, J.A.J., Huisman, E.A., Klapwijk, A., 2006. Design and operation of nitrifying trickling filters in recirculating aquaculture: a review. Aquacult. Eng. 34, 234-260.

Ellis, T., James, J., Scott, A., 2005. Branchial release of free cortisol and melatonin by rainbow trout. J. Fish Biol. 67, 535-540.

Ellis, T., James, J., Stewart, C., Scott, A., 2004. A non-invasive stress assay based upon measurement of free cortisol released into the water by rainbow trout. J. Fish Biol. 65, 1233-1252.

Ellis, T., James, J.D., Sundh, H., Fridell, F., Sundell, K., Scott, A.P., 2007. Non-invasive measurement of cortisol and melatonin in tanks stocked with seawater Atlantic salmon. Aquaculture 272, 698-706.

Fahrbach, M., Krauss, M., Preiss, A., Kohler, H.-P.E., Hollender, J., 2010. Anaerobic testosterone degradation in Steroidobacter denitrificans - identification of transformation products. Environ. Pollut. 158, 2572-2581. 
Fanouraki, E., Papandroulakis, N., Ellis, T., Mylonas, C.C.,Scott, A.P., Pavlidis, M., 2008. Water cortisol is a reliable indicator of stress in European sea bass, Dicentrarchus labrax. Behaviour 145, 1267-1281.

Feist, G., Schreck, C.B., 1990. Hormonal content of commercial fish diets and of young coho salmon (Oncorhynchus kisutch) fed these diets. Aquaculture 86, 63-75.

García-López, Á., Fernández-Pasquier, V., Couto, E., Canario, A.V.M., Sarasquete, C. Martínez-Rodríguez, G., 2006. Testicular development and plasma sex steroid levels in cultured male Senegalese sole Solea senegalensis Kaup. Gen. Comp. Endocrinol. 147, 343-351.

Gomes, R.L., Scrimshaw, M.D., Lester, J.N., 2009. Fate of Conjugated Natural and Synthetic Steroid Estrogens in Crude Sewage and Activated Sludge Batch Studies. Environ. Sci.Technol. 43, 3612-3618.

Horinouchi, M., Kurita, T., Yamamoto, T., Hatori, E., Hayashi, T., Kudo, T., 2004. Steroid degradation gene cluster of Comamonas testosteroni consisting of 18 putative genes from meta-cleavage enzyme gene tes $\beta$ to regulator gene tes $\beta$. Biochem. Biophys. Res. Commun. 324, 597-604.

Kime, D.E., Manning, N.J., 1982. Seasonal patterns of free and conjugated androgens in the brown trout Salmo trutta. Gen. Comp. Endocrinol. 48, 222-231.

Kolodziej, E.P., Harter, T., Sedlak, D.L., 2004. Dairy wastewater, aquaculture, and spawning fish as sources of steroid hormones in the aquatic environment. Environ. Sci. Technol. 38, 6377-6384.

Lambert, J., Resink, J., 1991. Steroid glucuronides as male pheromones in the reproduction of the African catfish Clarias gariepinus - a brief review. J. Steroid Biochem. Mol. Biol. 40, 549-556.

Liu, S., Ying, G.-G., Zhao, J.-L., Zhou, L.-J., Yang, B., Chen, Z.-F., Lai, H.-J., 2012. Occurrence and fate of androgens, estrogens, glucocorticoids and progestagens in two different types of municipal wastewater treatment plants. J. Environ. Monit. 14, $482-491$.

Maren, T.H., Embry, R., Broder, L.E., 1968. The excretion of drugs across the gill of the dogfish Squalus acanthias. Comp. Biochem. Physiol. 26, 853-864.

Martins, C.I.M., Eding, E.H., Verdegem, M.C.J., Heinsbroek, L.T.N., Schneider, O., Blancheton, J.P., d'Orbcastel, E.R., Verreth, J.A.J., 2010. New developments in recirculating aquaculture systems in Europe: a perspective on environmental sustainability. Aquacult. Eng. 43, 83-93.

Martins, C.I.M., Ochola, D., Ende, S.S.W., Eding, E.H., Verreth, J.A.J., 2009. Is growth retardation present in Nile tilapia Oreochromis niloticus cultured in low water exchange recirculating aquaculture systems? Aquaculture 298, 43-50.

Mommsen, T.P., Vijayan, M.M., Moon, T.W., 1999. Cortisol in teleosts: dynamics, mechanisms of action, and metabolic regulation. Rev. Fish Biol. Fish. 9, 211-268.

Moore, A., Scott, A.P., 1991. Testosterone is a potent odorant in precocious male Atlantic salmon (Salmo salar L.) parr. Philos. Trans. R. Soc. B 332, 241-244
Pelissero, C., Cuisset, B., Le Menn, F., 1989. The influence of sex steroids in commercial fish meals and fish diets on plasma concentration of estrogens and vitellogenin in cultured Siberian sturgeon Acipenser baeri. Aquat. Living Resour. 2, 161-168.

Rotllant, J., Guerreiro, P., Anjos, L., Redruello, B., Canario, A., Power, D., 2005. Stimulation of cortisol release by the $\mathrm{N}$ terminus of teleost parathyroid hormone-related protein in interrenal cells in vitro. Endocrinology 146, 71-76.

Scott, A., Inbaraj, R.M., Vermeirssen, E., 1997. Use of a radioimmunoassay which detects C21 steroids with a 17,20ß-dihydroxyl configuration to identify and measure steroids involved in final oocyte maturation in female plaice (Pleuronectes platessa). Gen. Comp. Endocrinol. 105, 62-70.

Scott, A., Sheldrick, E., Flint, A., 1982. Measurement of $17 \alpha, 20 \beta$-dihydroxy4-pregnen-3-one in plasma of trout (Salmo gairdneri Richardson): seasona changes and response to salmon pituitary extract. Gen. Comp. Endocrinol. 46 444-451.

Scott, A.P., Hirschenhauser, K., Bender, N., Oliveira, R., Earley, R.L., Sebire, M., Ellis T., Pavlidis, M., Hubbard, P.C., Huertas, M., 2008. Non-invasive measurement of steroids in fish-holding water: important considerations when applying the procedure to behaviour studies. Behaviour 145, 1307-1328.

Scott, A.P., Pinillos, M.L., Huertas, M., 2005. The rate of uptake of sex steroids from water by Tinca tinca is influenced by their affinity for sex steroid binding protein in plasma. J. Fish Biol. 67, 182-200.

Scott, A.P., Sorensen, P.W., 1994. Time course of release of pheromonally active gonadal steroids and their conjugates by ovulatory goldfish. Gen. Comp. Endocrinol. 96, 309-323.

Sorensen, P., Scott, A., Stacey, N., Bowdin, L., 1995. Sulfated 17, 20ß-dihydroxy4-pregnen-3-one functions as a potent and specific olfactory stimulant with pheromonal actions in the goldfish. Gen. Comp. Endocrinol. 100, 128-142.

Sorensen, P.W., Hara, T.J., Stacey, N.E., Dulka, J.G., 1990. Extreme olfactory specificity of male goldfish to the preovulatory steroidal pheromone $17 \alpha, 20 \beta$-dihydroxy4-pregnen-3-one. J. Comp. Physiol. A: Neuroethol. Sens. Neural. Behav. Physiol. $166,373-383$.

Sower, S.A., Iwamoto, R.N., 1985. The identification of the sex steroid, testosterone, in various commercial salmon diets. Aquaculture 49, 11-17.

Stacey, N., 2003. Hormones, pheromones and reproductive behavior. Fish Physiol Biochem. 28, 229-235.

Stacey, N., 2010. Hormonally derived sex pheromones in fishes. In: David, O.N. Kristin, H.L. (Eds.), Hormones and Reproduction of Vertebrates. Academic Press, London, pp. 169-192.

Stacey, N.E., Sorensen, P.W., 2006. Reproductive pheromones. In: Sloman, K.A Wilson, R.W., Balshine, S. (Eds.), Fish physiology, behaviour and physiology of fish, 24. Academic Press, Elsevier, pp. 359-412.

Vermeirssen, E.L.M., Scott, A.P., 1996. Excretion of free and conjugated steroids in rainbow trout (Oncorhynchus mykiss): evidence for branchial excretion of the maturation-inducing steroid, 17,20 $\beta$-dihydroxy-4-pregnen-3-one. Gen. Comp. Endocrinol. 101, 180-194. 